\title{
1 Improving atmospheric water production yield: enabling multiple water harvesting cycles with nano sorbent
}

3 Renyuan Li, Yusuf Shi, Mengchun Wu, Seunghyun Hong, and Peng Wang*

$4 \quad$ Water Desalination and Reuse Center, Division of Biological and Environmental Science and

5 Engineering, King Abdullah University of Science and Technology, Thuwal 23955, Saudi

6 Arabia.

$7 \quad *$ Corresponding author:

$8 \quad$ Email: peng.wang@kaust.edu.sa

\section{Abstract}

10 Clean water shortage has long been a challenge in remote and landlocked communities especially

11 for the impoverished. Atmospheric water is now considered as an unconventional but accessible

12 fresh water source and sorption-based atmospheric water generator (AWG) has been successfully

13 demonstrated a reliable way of harvesting atmospheric water. The water vapor sorbents with high

14 water uptake capacity and especially fast vapor sorption/desorption kinetics have become the

15 bottleneck to a desirable clean water productivity in AWG. In this work, we developed a new nano

16 vapor sorbent composed of a nano carbon hollow capsule with $\mathrm{LiCl}$ inside the void core. The

17 sorbent can capture water vapor from ambient air as much as $100 \%$ of its own weight under RH

$1860 \%$ within 3 hours and quickly release the sorbed water within just half hour under $1 \mathrm{~kW} / \mathrm{m}^{2}$

19 sunlight irradiation. A batch-mode AWG device was able to conduct 3 sorption/desorption cycles

20 within 10 hours during one day test in the outdoor condition and produced $1.6 \mathrm{~kg}_{\text {water }} / \mathrm{kg}_{\text {sorbent. }}$ A

21 prototype of continuous AWG device was designed, fabricated, and successfully demonstrated,

22 hinting a possible way of large-scale deployment of AWG for practical purposes. 


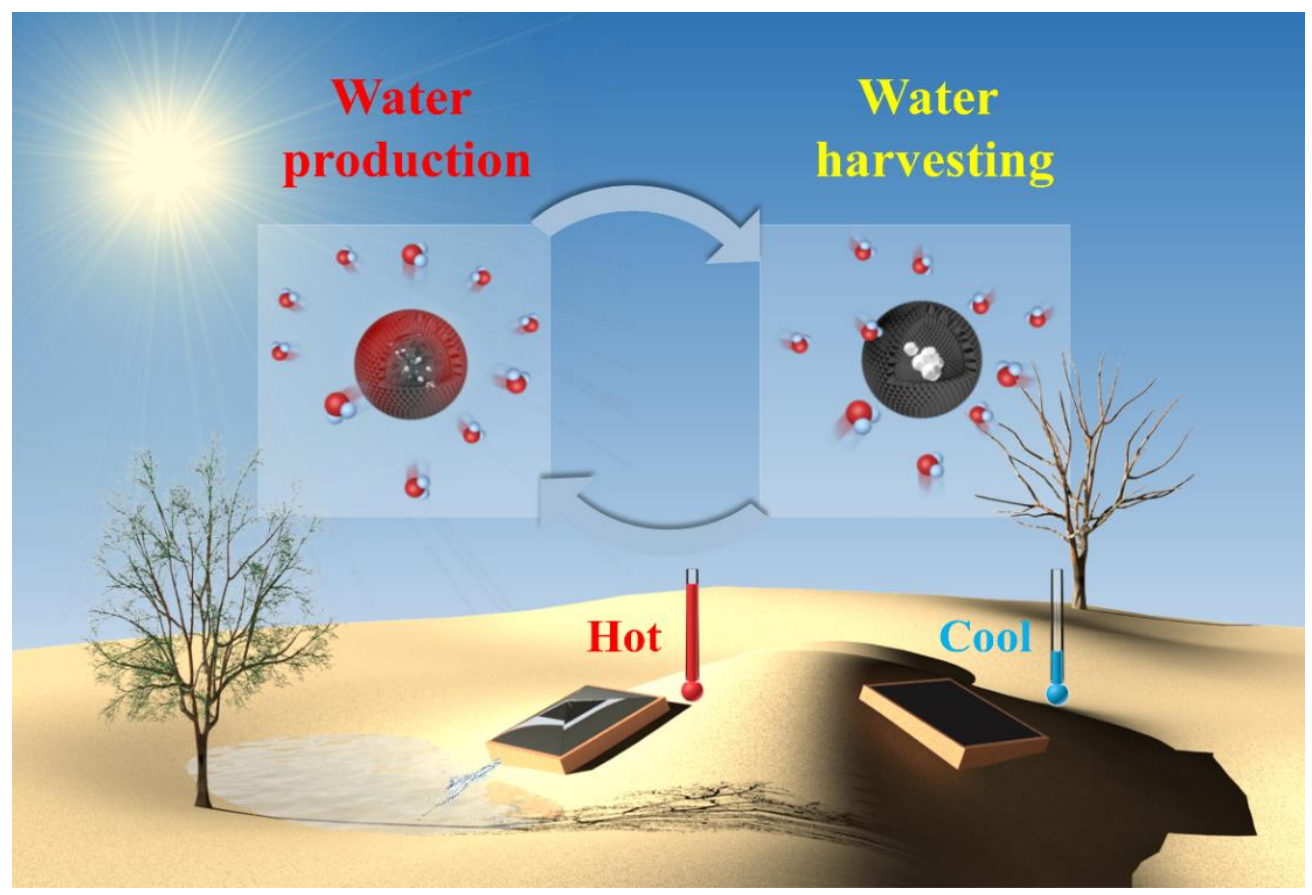

\section{Research Highlights:}

- Photothermal nano sorbents with high adsorption/desorption kinetics for atmospheric water harvesting

- Nanosized carbon shell providing improved light-trapping and in situ heat generation for uniformly and fast heating of the sorbent

- Multiple water vapor harvesting/water production cycles within one day due to the fast kinetics

- Continuous atmospheric water generator design for potential large and automated plantscale deployment

34 Keywords: Atmospheric water harvesting, nanocapsule, vapor sorbent, photothermal material 


\section{Introduction}

37 Water scarcity is one of the greatest challenges and it is affecting two-thirds of the world's population [1-3]. Energy-intensive approaches, such as seawater desalination [4-7] and wastewater reuse $[8,9]$, are being engaged to augment clean water production to tenuously meet the evergrowing water demand due to the fast growing population $[6,8]$. However, these technologies are either not affordable by impoverished communities or impractical to the communities in the landlocked regions with very limited access to water resource [10-11]. For the latter, reliance on long distance pipe transportation for fresh water becomes essential but expensive expenditure of the local economy, which is widely deemed non-sustainable [12-14]. It has been reported that more than 783 million people has no direct access to safe drinking water due to the impoverished conditions [15]. On the other hand, Earth's atmosphere always holds a substantial amount of water in the forms of vapor and droplets. The atmospheric water is estimated to be approximately 12,900 billion tons, equivalent to 6 times of water in all rivers on Earth [16]. In addition, the removal of atmospheric water is quickly compensated as an integral part of the global hydrologic cycle [17], ultimately driven by inexhaustible solar energy [17-18]. Given the fact that the seawater covers $71 \%$ of Earth's surface [16], the atmospheric water can be considered as an unconventional but easily accessible fresh water source continuously desalinated and replenished by Sun $[19,20]$.

Several atmospheric water harvesting (AWH) technologies have been investigated during past decades, but they are met with limited success [21-24]. For example, fog harvesting requires consistently high relative humidity (RH) (i.e., typically RH 100\%) [25-28]. The refrigerationbased dew water consumes electricity as high as $\sim 1000 \mathrm{kWh}$ for each cubic meter water produced in the climate conditions of $\mathrm{RH} 62 \%, 30{ }^{\circ} \mathrm{C}$. When the humidity drops to $20 \%$, the energy consumption could jump to $\sim 5000 \mathrm{kWh}$ per cubic meter water production [29-31]. Emerging nowadays is the sorption-based AWH process, which involves water vapor sorbents to harvest water vapor from ambient air and solar photothermal process to release and the condensate water is collected as fresh water product [24]. Even though the energy consumption could be high for the regeneration process of water vapor sorbent, the energy source for the regeneration of sorbent could be achieved by using low-grade energy such as solar energy or waste heat [24,31]. The advantage of the sorption-based AWG design is that the thermal sources can be used to drive the water harvesting process and thus it does not consume electricity. It works even for dry regions 
with low RH, and can lead to simple, affordable, and all-in-one devices for decentralized and pointof-use (POU) year-around fresh water production, which makes it a potential solution to those who lack economical access to safe drinking water [32-36].

The thermodynamic and kinetic properties of the water sorbents are both key factors in the sorption-based AWH [37]. In 2017, Yaghi and Wang et al. successfully demonstrated the concept of use unconventional water vapor sorbent (i.e., metal-organic-framework, MOF) to extract water vapor from dry air with relative humidity as low as $20 \%$ and the water can be released by natural sunlight through photothermal process [38]. This concept was further investigated with an enlarged scale and demonstrated to be feasible in the arid climate $[39,40]$. In the following years, a few water sorbents with high water vapor sorption capacities and suitable absorption enthalpy have been reported [41-44]. However, the slow kinetics becomes a bottleneck: it took more than ten and several hours to release water for condensate collection under normal sunlight $[41,42]$. These limitations resulted the current sorbents for AWH to work only in batch mode and to complete only one sorption/desorption cycle every day. The batch mode makes it infeasible to deploy this technology to large-scale water production. Thermodynamically speaking, water vapor sorption can take place during daytime so long as there are suitable humidity and temperature. As a result, it is hypothesized that multiple or even continuous sorption-desorption cycles can be designed based on special water vapor sorbent with fast water sorption and water release kinetics. Under this premise, fresh water productivity can be enhanced with reduced weight of the sorbent.

Toward proving the hypothesis, in this work, we designed and fabricated a nano-sized photothermal water vapor sorbent with significantly enhanced vapor sorption and release kinetics. Hollow nanocapsule of $\sim 300 \mathrm{~nm}$ in diameter was produced, inside which hygroscopic salt $\mathrm{LiCl}$ was encapsulated. In the design, $\mathrm{LiCl}$ acts as the active vapor sorption agent and carbon capsule serves as a container of $\mathrm{LiCl}$ and at the same time as the photothermal component. When packed, the space within the nano sorbent stack among the spherical nano sorbents (i.e., interparticle space) acts as the highway for water vapor transport. The advantages of the nano-design are: (1) high specific surface area for water vapor to access; (2) better light-trapping and in situ heat generation to minimize heat loss during heat transfer and to uniformly and fast heat up the sorbent from all directions; and (3) confinement of salt and thus sorbed water inside a solid container to avoid 
interparticle water vapor channel collapse. In our design, the diffusion length of water vapor inside the capsule is less than $150 \mathrm{~nm}$, which is $4-5$ order of magnitude shorter than that in liquid sorbents or hydrogel-based solid sorbents [42]. The nano sorbent can capture water vapor from surrounding ambience as much as $100 \%$ of its own weight under RH $60 \%$ within 3 hours. The sorbed water can be quickly released within half hour under $1 \mathrm{~kW} / \mathrm{m}^{2}$ sunlight irradiation.

This work assembled a batch-process based AWH device using easily-accessible materials. The AWH device was tested in the outdoor condition and successfully conducted 3 sorption-desorption cycles within 10 hours during one day. The water production yield in the field test reached as high as $1.6 \mathrm{~kg}_{\text {water }} / \mathrm{kg}_{\text {sorbent }}$ per day. A prototype of continuous AWG device was further fabricated based on the nano sorbent, which produced $0.86 \mathrm{~kg}$ water per each $\mathrm{kg}$ of nano sorbents in one day. Even though its apparent water production yield is not as high as the batch-based AWH device, the continuous AWH design provides a possible solution to the large and automated plant-scale deployment. To the best of our knowledge, this work reports the first sorption-based continuous AWG device. This work sheds significant light on progression from batch-based AWH process to continuous AWH process and would spark a lot of research passions to produce effective AWG for wide and practical applications.

\section{Materials and methods}

\subsection{Chemicals and materials.}

114 Styrene (99\%) and potassium persulfate (KPS, 99\%) were purchased from Acros Organics. Oleic acid was purchased from Riedel-de Haën. Phenol (99\%), lithium chloride (LiCl, 98\%) and

116 hexamethylenetetramine (99\%) were purchased from Sigma-Aldrich. Deionized (DI) water (18.2 $117 \mathrm{M} \Omega$, from Milli-Q system) was used throughout the experiments.

\subsection{Material characterization.}

Transmission electron microscopy (TEM) investigations were carried out on an FEI Titan-ST microscope. Scanning electron microscope (SEM) images were obtained on an FEI Magellan 400 microscope. Nitrogen adsorption test was measured with a Micromeritics Tristar 3020 adsorption analyzer. The X-ray photoelectron spectroscopy (XPS) analysis was conducted on a Kratos AXIS

123 Supra XPS spectrometer. The UV-vis-NIR spectra were obtained on a PerkinElmer Lambda 950 124 spectrophotometer. Water sorption properties were investigated on a NETZSCH Jupiter 
simultaneous thermal analyzer (STA)-449 measurement system coupled with a modular humidity generator (MHG, ProUmid). Temperature curves and infrared (IR) images of the samples were recorded by a FLIR A655 IR camera. Thermal conductivity was measured by a set of laser flash apparatus (LFA 447 NanoFlash ${ }^{\circledR}$, Netzsch) system with a powdery sample holder.

\subsection{Fabrication of hollow carbon sphere (HCS)-LiCl nano sorbent.}

Polystyrene (PS) nanospheres were synthesized as hard templates in this work. $7 \mathrm{ml}$ of styrene and $188 \mu \mathrm{L}$ of oleic acid were mixed and dispersed in $272 \mathrm{~mL}$ DI water. The mixture was stirred at 50 ${ }^{\circ} \mathrm{C}$ for 1 hour, followed by adding $160 \mathrm{mg}$ of KPS. The solution was heated to $70{ }^{\circ} \mathrm{C}$ under magnetic stirring for 5 hours. The final product was filtrated and washed by DI water. All the steps were performed under a nitrogen atmosphere.

The hollow carbon spheres (HCS) were prepared in the following steps: $225 \mathrm{mg}$ of PS spheres were dispersed in $150 \mathrm{~mL}$ of DI water. Then $30 \mathrm{~mL}$ of aqueous solution with phenol $(264 \mu \mathrm{L})$ and hexamethylenetetramine $(0.21 \mathrm{~g})$ was added. The solution was transferred into a teflon-lined autoclave, heated at $160{ }^{\circ} \mathrm{C}$ for 4 hours followed by centrifugation and washed for several times with DI water (PS@PF sphere). The washed PS@PF spheres were dried in a box-type oven at 70 ${ }^{\circ} \mathrm{C}$ for 12 hours. The as-obtained PS@ PF spheres were transferred to a tube furnace with a nitrogen atmosphere, heated to $150{ }^{\circ} \mathrm{C}$ with a ramp of $5{ }^{\circ} \mathrm{C} / \mathrm{min}$ and dwelled for 1 hour. The temperature was then raised to $800^{\circ} \mathrm{C}$ with a ramp of $5^{\circ} \mathrm{C} / \mathrm{min}$ and kept at this temperature for 2 hours, followed by cooling down to room temperature naturally [45].

The HCS-LiCl nano sorbents were obtained by immersing HCS in the saturated $\mathrm{LiCl}$ ethanol solution followed by vacuuming for 2 minutes. Then the HCS- $\mathrm{LiCl}$ was collected by vacuum assisted filtration and then dried in a box-type oven for 2 hours with a temperature of $75^{\circ} \mathrm{C}$. The infiltration process was repeated for 2 times. The weight content of carbon in the HCS-LiCl nano sorbent was estimated by the CHNS-O element analyzer (FLASH 2000, Thermo Scientific) and Energy-dispersive $\mathrm{X}$-ray spectroscopy (EDS). Then the $\mathrm{LiCl}$ weight content was calculated by the deduction of carbon weight from the total. The volume content of $\mathrm{LiCl}$ in the vacancy of the HCS$\mathrm{LiCl}$ was estimated based on the electron microscopic characterization (details can be found in supporting information).

\subsection{Water sorption/desorption experiments.}


The water vapor sorption/desorption performance of $\mathrm{HCS}-\mathrm{LiCl}$ was tested by a stimultaneous thermal analyzer (STA)-modular humidity generator (MHG) system under static humidity mode. The STA furnace was first heated up from $25^{\circ} \mathrm{C}$ to $80{ }^{\circ} \mathrm{C}$ to dehydrate the nano sorbent and then cooled down to $25{ }^{\circ} \mathrm{C}$ for the water vapor sorption test. The sorption test was carried on for 13 hours, and then the furnace of STA was programmed to heat up to $80{ }^{\circ} \mathrm{C}$ to investigate the desorption property of the nano sorbent. Both the cooling and heating ramp was $5{ }^{\circ} \mathrm{C} / \mathrm{min}$. Four different humidity conditions (i.e., RH 15, 35, 60 and 80\%) were investigated by purging the MHG generated wet nitrogen flow with specified RH into the STA furnace. The temperature of the nitrogen flow was maintained at $25^{\circ} \mathrm{C}$ throughout the test. Water vapor absorption isotherms of HCS-LiCl were characterized by a dynamic adsorption analyzer (DVS analyzer, IGAsorp-CT, Hiden Isochema) at $25^{\circ} \mathrm{C}$ and $35^{\circ} \mathrm{C}$. Prior to the analysis, the sample was in situ pre-dried at 80 ${ }^{\circ} \mathrm{C}$ for 3 hours. The stability of the HCS-LiCl was investigated by a STA-MHG system for 10 dynamic absorption-desorption cycles. Each cycle consisted of a water vapor sorption section (10 h, RH $80 \%, 25{ }^{\circ} \mathrm{C}$ ) and a water release section $\left(1.5 \mathrm{~h}, \mathrm{RH} 10 \%, 80^{\circ} \mathrm{C}\right)$. A pre-heat cycle was applied to the sample prior the cycling test to ensure the dry state of the sample. The humidity was maintained by a MHG-generated nitrogen flow, with a constant temperature of $25{ }^{\circ} \mathrm{C}$ and an alternated RH between $10 \%$ and $80 \%$ based on the sorption/desorption sections of the experiments. The water vapor sorption behavior of $\mathrm{HCS}-\mathrm{LiCl}$ nano sorbent and pure $\mathrm{LiCl}$ salt was also investigated in the outdoor condition. $5 \mathrm{~g}$ of $\mathrm{HCS}-\mathrm{LiCl}$ and $5 \mathrm{~g}$ of $\mathrm{LiCl}$ salt were placed in the plastic petri dish (dimeter $10 \mathrm{~cm}$ ), and the weight change of both samples was recorded by an electric balance. The ambient condition was monitored and recorded by a LogTag humidity \& temperature recorder. The outdoor test was conducted on KAUST campus, Thuwal, KSA, from 19:00-23:00 local time (GMT+3), and the sampling time was set to be $5 \mathrm{~min}$.

The photothermal assisted water release property of $\mathrm{HCS}-\mathrm{LiCl}$ was investigated under simulated sunlight (Oriel solar simulator, 94023A). The HCS-LiCl nanospheres were placed on a fibrous silica substrate and exposed to $60 \% \mathrm{RH}$ atmosphere for 2 hours at room temperature $\left(22^{\circ} \mathrm{C}\right)$ prior test. IR camera and electronic balance were employed to record the temperature and weight change of the nano sorbent. The test was carried out under 5 different light strength (i.e., 0.7, 0.8, 0.9, 1.0, and $1.1 \mathrm{~kW} / \mathrm{m}^{2}$ ).

\subsection{Batch-mode AWH device fabrication and the outdoor performance measurement.}


To investigate the water production performance of HCS-LiCl nano sorbent in field condition, a batch-process based, all-in-one device was fabricated. A metallic cookie box (dimension $20 \times 20$ $\times 5 \mathrm{~cm}^{3}$ ) was used as the container and $12.6 \mathrm{~g}$ of pre-dried HCS-LiCl nano sorbent was placed inside a glass dish with diameter of $14 \mathrm{~cm}$. The box was put outdoor overnight uncovered (21:00 on March 20 to 8:10 on March 21, 2019 KSA time). The device was covered with a kitchen plastic wrap next morning (8:20 am on March 21, 2019) and put on the rooftop of a town house inside KAUST campus (Thuwal, KSA). After 80 minutes sunlight irradiation, the condensed water inside metal box/on the surface of plastic wrap was collected. The box was then moved under a shaded area to prevent direct sunlight exposure to sorb water vapor from air for the next 2 hours (9:4511:45am). The second water release and collection was conducted between 11:50-13:10. The third water vapor sorption-desorption/collection was conducted from 13:20 to 15:20. Due to sunlight strength attenuation, the device was aligned to facing the sunlight in the third cycle with extended irradiation time (15:30 to 17:30). The solar power meter was placed perpendicular to the rooftop where the experiment was conducted. The relative humidity meter recorded the value on the beginning time of two individually water vapor sorption process.

Inductively coupled plasma-optical emission spectroscopy (ICP-OES, Agilent 5110) equipped with a charge-coupled device (CCD detector) and a charge injection device (CID detector) was used to investigate the concentration of lithium and iron in the water sample produced from the outdoor experiment. Total organic compound (TOC) analyzer (TOC-L, Shimadzu) was employed to test the TOC concentration in the same water sample.

\subsection{Continuous atmospheric water generator (AWG).}

A continuous atmospheric water generator (AWG) was designed and fabricated based on the HCS$\mathrm{LiCl}$ nano sorbent, which included three major parts: a central rotational cylinder, a copper condenser with transparent cap, and a frame with stepper motor. HCS-LiCl nano sorbent was loaded onto the fibrous silica filter paper and mounted and wrapped around the rotational cylinder with a mass loading of $0.03 \mathrm{~g} / \mathrm{cm}^{2}$ ( $2.93 \mathrm{~g}$ in total). The stepper motor was set to drive the cylinder with a varied rotation rate (i.e., $0.5,0.75,1.5$ and 4 revolution per hour, rph). The whole device was placed under simulated sunlight with a light strength of $1.0 \mathrm{~kW} / \mathrm{m}^{2}$.

\section{Results and discussions}


In this work, we present a novel kinetic-enhanced nano-scaled water vapor sorbent for continuous AWG application. The nano sorbent is composed of a highly hygroscopic salt (i.e., $\mathrm{LiCl}$ ) core and a porous photothermal shell (hollow carbon sphere). The hygroscopic salt is capable of sorbing a large quantity of water from the surrounding air even when the humidity is low (i.e. RH 15-35\%). The hollow carbon sphere, on the one hand, holds and isolates the hygroscopic salt as a small and individual sorption unit, while generates inter-particle space for water vapor transport. On the other hand, the HCS absorbs sunlight at its surface, and in-situ heats up the saturated nano sorbent through the photothermal process. All these allow for drastic water vapor sorption/desorption kinetic enhancement, leading to it superior water harvesting and production performance.

\subsection{Synthesis of HOC-LiCl nano sorbent.}

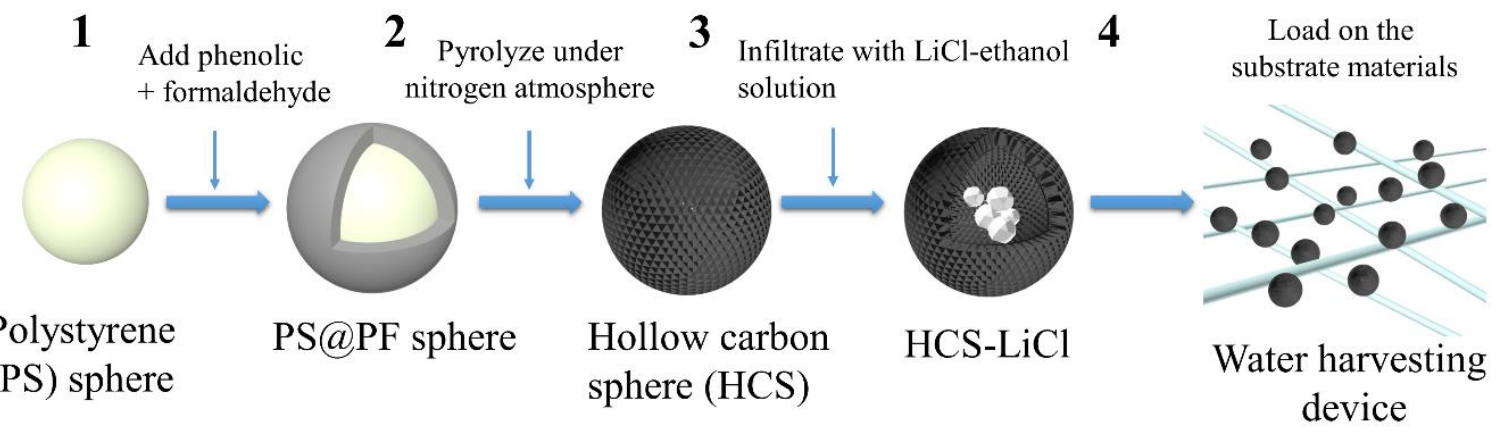

Fig. 1. Schematic of HCS-LiCl nano sorbent fabrication process. Step 1: Coating of PF layer on the surface of PS hard template. Step 2: Pyrolysis of PS@PF to obtain HCS. Step 3: LiCl infiltration. Step 4: Embedment of nano sorbent to the fibrous silica substrate.

The HCS-LiCl nano sorbent was synthesized through a hard-template method by using polystyrene (PS) spheres as the core templates [45]. The PS spheres were prepared by the popular emulsion polymerization method, whose surfaces were uniformly coated with a layer of phenolicformaldehyde (PF) via hydrothermal method (Fig. 1, step 1). The as-obtained PS@PF spheres were transferred to a tube furnace for high-temperature pyrolysis during which the PF layer was converted into carbon while the PS core was decomposed, leading to formation of hollow carbon spheres (Fig. 1, step 2). Due to the hydrophobic property of HCS after high-temperature pyrolysis, $\mathrm{LiCl}$ ethanol solution was used to embed $\mathrm{LiCl}$ salt into the as-obtained HCS under vacuum (Fig. 1, step 3, and Fig. S1). In this work, fibrous silica filter was used as the substrate to hold the HCSLiCl nano sorbent (step 4 of Fig. 1, and Fig. S2). 
TEM observation reveals that the average diameter of PS is $\sim 240 \mathrm{~nm}$ (Fig. 2a). After coated with

238 PF layer, the diameter of nanosphere increased to $\sim 300 \mathrm{~nm}$, indicating the thickness of the PF resin 239 layer was $\sim 30 \mathrm{~nm}$ (Fig. 2b). After pyrolysis treatment, the size of HCS was similar to that of 240 PS@PF nanspheres (Fig. 2c). After LiCl was loaded, the dimension of HCS-LiCl remained almost 241 unchanged comparing with HCS (Fig. 2d). Fig. 2e and f show the selective area electron diffraction 242 (SAED) patterns of HCS and HCS-LiCl. For HCS, only dispersing diffraction rings were obtained, 243 indicating the amorphous carbon shell. When the HCS was loaded with $\mathrm{LiCl}$, an extra set of 244 diffraction pattern indexed to (200), (111) plane of $\mathrm{LiCl}$ was observed [46]. The high-resolution 245 TEM (HRTEM) image of the shell showed a typical amorphous carbon structure, consistent with 246 the SAED result. As can be seen in Fig. 2 g, the HCS wall shows a rough and porous surface. Fig. $2472 \mathrm{~h}$ and $\mathrm{i}$ are the SEM images of HCS and HCS-LiCl, further confirming the size of nanospheres 248 before/after the salt loading. Fig. 2j-1 are the SEM-EDS mapping of HCS-LiCl. Since lithium 249 element is invisible in EDS, only carbon and chloride were analyzed and mapped. The distribution 250 of chloride perfectly matched the carbon element mapping, indicating a successful loading of $\mathrm{LiCl}$.
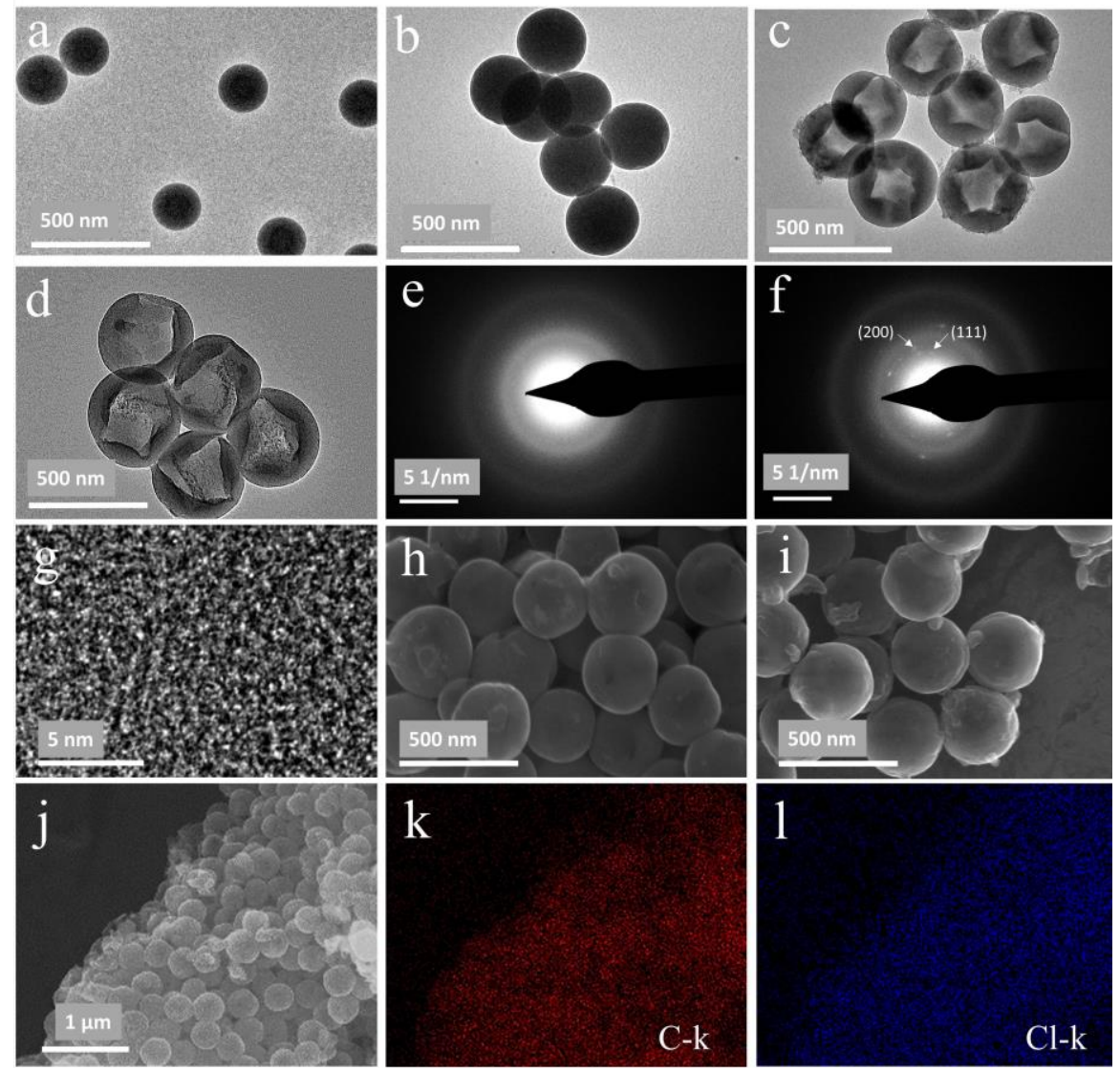
Fig. 2. (a)-(d) TEM images of (a) PS, (b) PS@ PF, (c) HCS, and (d) HCS-LiCl, respectively. SAED patterns of (e) HCS and (f) HCS-LiCl. (g) The HRTEM image of HCS. SEM images of (h) HCS and (i) HCS-LiCl. (j)-(l) SEM-EDS mapping of HCS-LiCl.

Light absorbance of HCS loaded fibrous silica filter was tested with an UV-vis-NIR spectrophotometer with silica filter as background (Fig. 3a). As can be seen, HCS showed an outstanding light absorbance throughout the whole spectrum (>92\%). The relative light absorption rate for the materials to sunlight was calculated to be $94.47 \%$ and the spectrum has been displayed in Fig. S3. The wetting behavior of HCS was tested indirectly through $\mathrm{LiCl}$ solution contact angle and chemical composition investigation. The $\mathrm{LiCl}$ solution contact angle of the HCS loaded fibrous silica filter was $137.5^{\circ}$ (Fig. S4), indicating that the HCS was highly hydrophobic. The wetting behavior of $\mathrm{LiCl}$ water solution also explained the reason why a less polar solvent, ethanol, was used during $\mathrm{LiCl}$ infiltration process. Fig. 3b shows the X-ray photoelectron spectroscopy (XPS) survey spectrum of HCS, indicating $94.9 \%$ of the elements in HCS was carbon. The highresolution spectrum of $\mathrm{C} 1 \mathrm{~s}$ is shown in Fig. 3c. Five components were fitted with the $\mathrm{C} 1 \mathrm{~s}$ spectrum, located at $284.4,285.1,286.4$, and $288.9 \mathrm{eV}$, corresponding to the $\mathrm{C}=\mathrm{C}$ ( $\mathrm{sp}^{2}$ hybridized carbon), $\mathrm{C}-\mathrm{C}$ ( $\mathrm{sp}^{3}$ hybrid carbon), $\mathrm{C}-\mathrm{O}-\mathrm{C}$, and $\mathrm{C}=\mathrm{O}$ groups [47]. The atomic ratio of $\mathrm{C} / \mathrm{O}$ in the HCS sample is 21.1, indicates the lack of polar groups in the material, thus lead to a hydrophobic property of HCS. The hydrophobic property towards LiCl solution of HCS is a critical factor to ensure the hygroscopic salt core can be tightly preserved inside the HCS shell even when it is turned into liquid by deliquescence. This otherwise salt leakage outside of HCS will lead to very undesirable loss of the salt and clogging of water vapor channels. The nitrogen adsorption measurement showed microporosity of HCS with a surface area of $620 \mathrm{~m}^{2} / \mathrm{g}$ (Fig. 3d, Fig. S5). These results prove that HCS has an outstanding light absorption property, is hydrophobic in wettability, and has highly porous wall, all of which are desired for effective and fast water vapor sorption/desorption. Besides, the heat conductivity of the HCS stack was measured to be $\sim 0.316$ $\mathrm{W} /\left(\mathrm{m}{ }^{\circ} \mathrm{C}\right)$, which could be attributed by the contact thermal resistance between the adjacent particles. Given the measured thermal conductivity, the further improvement in thermal conduction of the system can be made by using substrates with superior heat conductivity (i.e. stainless steel woven, carbon block, etc.), reducing the thickness of sorbent layer, among others. 


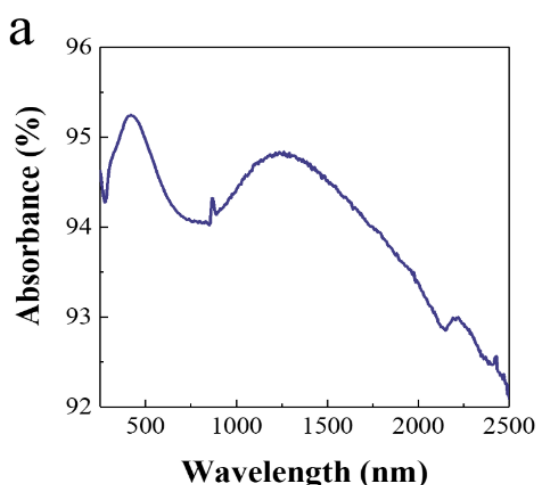

b

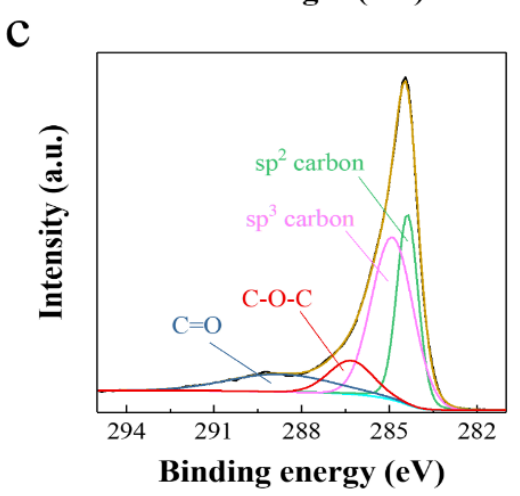

d
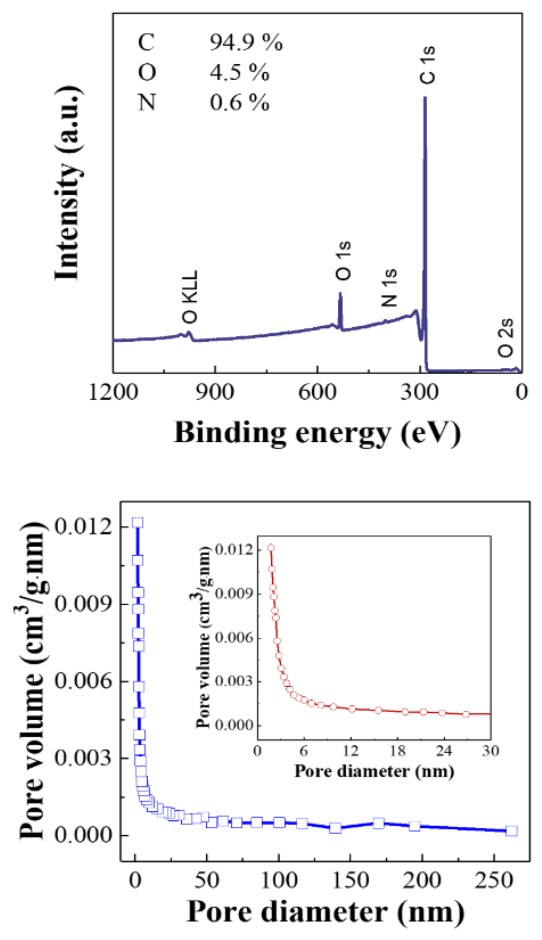

282 Fig. 3. (a) UV-vis-NIR spectra of HCS loaded on the fibrous silica filter. (b) XPS survey spectrum of HCS. (c) XPS spectra of C 1s. (d) Pore size distribution of HCS. Inset is the distribution pattern 284 in the range of $0-30 \mathrm{~nm}$.

\subsection{Water sorption/desorption assessment.}

286 Theoretically, desorption of saturated sorbent is an active process where the sorbents are heated 287 up by the external heat source. In contrast, sorption of water vapor onto the sorbent is a passive 288 process where the diffusion kinetics of water vapor plays an important role in the overall sorption rate. In practical application, it may take only a few hours for the water sorbent to release water but a significantly longer time to recover back to its saturation state.

291 The water sorption behaviors of the HCS-LiCl nano sorbent were first investigated under static 292 humidity condition. A simultaneous thermal analyzer (STA) coupled with a modular humidity 293 generator (MHG) was employed for the water sorption/desorption assessment. At the first stage, 294 the STA furnace was programmed to heat up to $80{ }^{\circ} \mathrm{C}$ for dehydration purpose. After the 295 dehydration process, the furnace was cooled down to $25^{\circ} \mathrm{C}$ and maintained throughout the sorption test (i.e., 13 hours). After the sorption test was completed, the furnace was heated back to $80{ }^{\circ} \mathrm{C}$ to 
investigate the desorption property of the nano sorbent. Humidity generator was programmed to purge carrier nitrogen gas with pre-defined relative humidity (i.e., RH 15, 35, 60, and 80\%) into the STA furnace throughout the test.
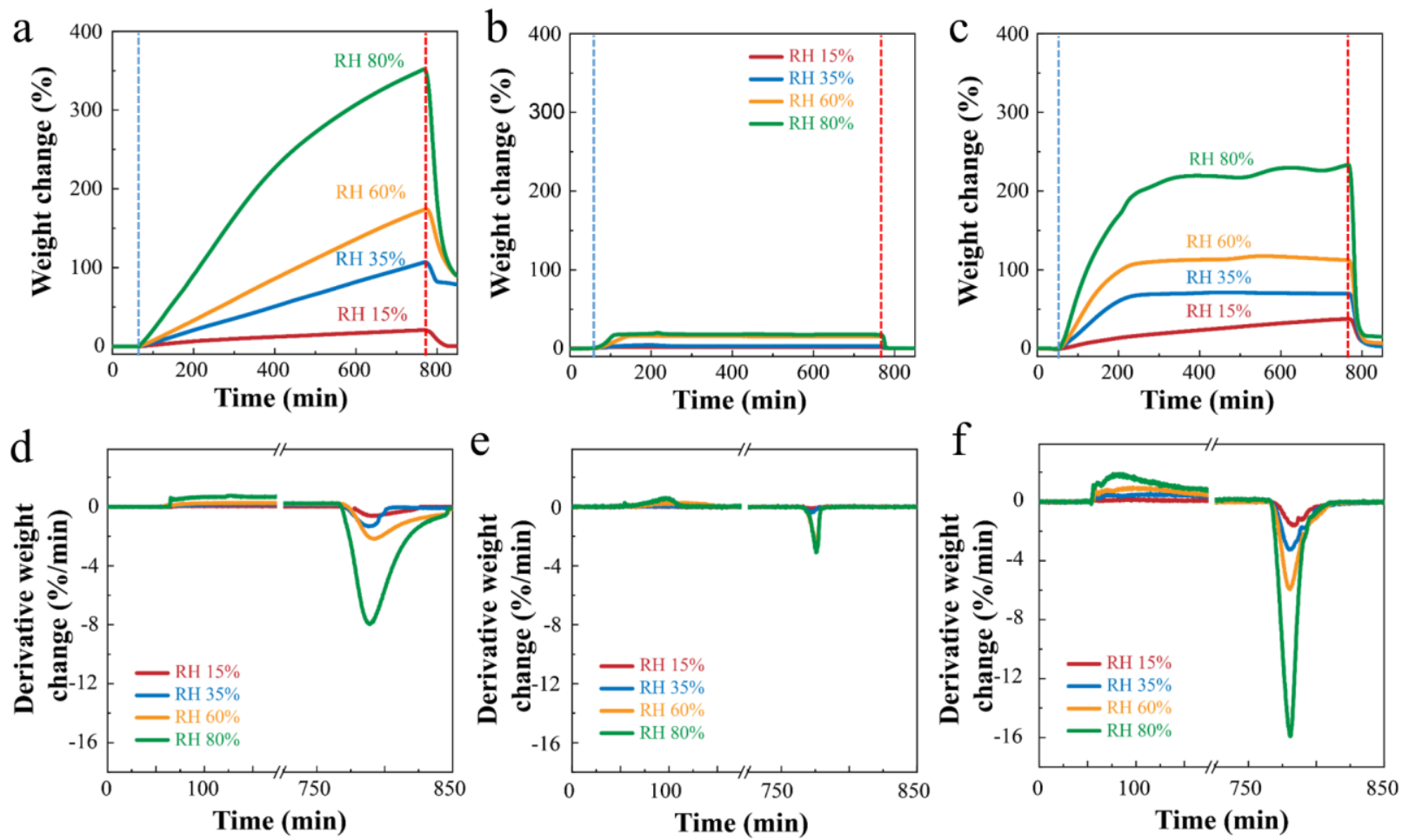

301

Fig. 4. (a)-(c) Static RH tests of $\mathrm{LiCl}, \mathrm{HCS}$, and HCS-LiCl under different RH conditions. The blue dash line indicates the start point of water vapor sorption process while the red dash line indicates the end of the absorption section and the beginning of the desorption section. (d)-(f) Derivative weight changes of $\mathrm{LiCl}, \mathrm{HCS}$, and $\mathrm{HCS}-\mathrm{LiCl}$ under different static RH conditions.

Fig. 4a shows the static humidity test result of pure LiCl. The water uptake (i.e., weight change in Y-axis) of $\mathrm{LiCl}$ showed a drastic increase at $\mathrm{RH} 35,60$, and $80 \%$. By the end of the test, the water uptake were $20.35,106.43,173.89$, and $351.8 \%$ of the $\mathrm{LiCl}$ salt's own weight for $15,35,60$, and $80 \% \mathrm{RH}$, respectively. $\mathrm{LiCl}$ salt was liquefied and its water vapor sorption equilibrium was not achieved even after 13 hours of the test. For the desorption process under $80{ }^{\circ} \mathrm{C}$, the $\mathrm{LiCl}$ failed to release all of its absorbed water within the test time (i.e. 90 min). For HCS without LiCl, the weight changes due to water sorption were $1.72,3.18,15.76$, and $17.83 \%$ of its own weight at $15,35,60$, and $80 \% \mathrm{RH}$, respectively (Fig. 4b), which is negligible comparing with the weight change of $\mathrm{LiCl}$ (Fig. 4a). Fig. 4c shows the sorption behavior of HCS-LiCl. As can be seen, the sorption saturation 
was achieved within 4 hours, and the final sorbed water were $22,70,112$, and $220 \%$ at 15, 35, 60, and $80 \% \mathrm{RH}$, respectively. Furthermore, more than $90 \%$ of the water uptake was achieved within the first 3 hours. During vapor sorption, $\mathrm{LiCl}$ turns into liquid droplets and the small droplets coalesce and form bigger ones, leading to reduced contact surface area with air. Concentrationgradient drives water molecules to diffuse from the surface towards the droplet core, with $\mathrm{Li}^{+} / \mathrm{Cl}^{-}$ ions diffusing in an opposite direction. As the droplets further grow in size, the diffusion length will be increased, further limiting the sorption kinetics. For the LiCl-HCS nano sorbent, the HCS limits the size of the $\mathrm{LiCl}$ droplet to several hundred nanometers and thus promotes the overall sorption/desorption kinetics. Unlike $\mathrm{LiCl}$, a plateau was observed for HCS-LiCl under RH 35, 60, and $80 \%$, which may attributed to the spatial limitation by HCS capsule structure and limited amount of $\mathrm{LiCl}$ loaded into the HCS. The sorbed water in $\mathrm{HCS}-\mathrm{LiCl}$ could be very quickly released within half hour, indicating much enhanced kinetics comparing with $\mathrm{LiCl}$. The weight content of carbon in the HCS-LiCl nano sorbent was estimated to be 64\% (CHNS-O element analyzer) and $69.75 \%$ (EDS) thereby the weight content of $\mathrm{LiCl}$ was calculated to be $30.25 \%$ and $36 \%$. Since EDS is more accurate in measuring heavy elements, the observed weight content from EDS can be used as a comparison and show the accuracy of element analyzer (Fig. S5). The volume percentage of $\mathrm{LiCl}$ within the vacancy of $\mathrm{HCS}$ was calculated to be $17.4 \%$, indicating more than $80 \%$ of the vacancy available for water storage (Supplementary note 1, Fig. S6).

The derivative weight change of all three samples were plotted and compared (Fig. 4d-f, Fig. S7 and Fig. S8). As seen, during the sorption process, the $\mathrm{LiCl}$ had an almost constant sorption rate in the first 6 hours, which then slowly dropped to almost zero by the end of the test. When $\mathrm{LiCl}$ solution absorbs water, the concentration of $\mathrm{LiCl}$ decreases and its vapor pressure increases. Thus, it is noteworthy that, while the partial pressure of water vapor inside STA furnace is not changed (i.e. constant temperature and $\mathrm{RH}$ ), the vapor sorption by the sorbent will be reduced as the sorption goes on. For HCS, a small peak in derivative weight change was observed at the beginning of the test, followed by a quick drop to zero. The derivative weight change of HCS-LiCl firstly had a rapid increase within the first 25 minutes, and then slowly dropped back to zero at $\sim 200 \mathrm{~min}$. Most importantly, the peak sorption rate of $\mathrm{HCS}-\mathrm{LiCl}$ almost tripled the sorption rate of LiCl. For the desorption process, the derivative weight change of all three samples was proportional to their respective water uptake. For $\mathrm{HCS}-\mathrm{LiCl}$, the peak value of derivative weight change was double of the value of $\mathrm{LiCl}$, even it had a smaller water uptake than that of $\mathrm{LiCl}$, which demonstrates the 
successful improvement of kinetic property. Comparing with the bulk/liquid-phased water vapor sorbent such as hydrogel or liquid desiccant, the occupation rate of the spherical nano sorbent, even densely packed as the hexagonal close packing form, is only $74 \%$. Thus, the rest of $26 \%$ empty space (i.e., interparticle space, see Supplementary note 2 and Fig. S9 for more details) can be used as the channels for water vapor transportation. The diffusion length can be significantly decreased to the radius of the individual sphere, which is in hundreds of nanometer. The superior performance of $\mathrm{HCS}-\mathrm{LiCl}$ in both sorption and desorption can be attributed to its enlarged specific area and unblocked water vapor channel (Fig. S10). These properties make it a good candidate as the water vapor sorbent for AWG devices with fast water sorption/desorption property.

The water vapor sorption behavior of $\mathrm{HCS}-\mathrm{LiCl}$ and pure $\mathrm{LiCl}$ salt was subsequently compared in the outdoor condition with an enlarged sorbent mass scale. As can be seen from Fig. S11a, the ambient temperature and the relative humidity during the outdoor teat was $\sim 32{ }^{\circ} \mathrm{C}$ and $\mathrm{RH} 50-60 \%$, respectively. Fig. S11b displays the time-dependent weight change profiles of $\mathrm{LiCl}$ and $\mathrm{HCS}-\mathrm{LiCl}$ during the outdoor water vapor sorption test. At the initial stage (i.e. $\sim 0-25 \mathrm{~min}$ ), the water vapor sorption rate of $\mathrm{LiCl}$ was slightly higher than that of HCS-LiCl. After that, HCS-LiCl nano sorbent showed a faster sorption rate. In $\mathrm{HCS}-\mathrm{LiCl}, \mathrm{LiCl}$ salt was incorporated inside the carbon capsule, while for pure $\mathrm{LiCl}$ sample, it started as solid phase. Thereby, at the beginning of the test before the deliquescence of $\mathrm{LiCl}$ solid, the pure $\mathrm{LiCl}$ sample showed a slightly faster kinetics than HCS$\mathrm{LiCl}$. After a short period of time, $\mathrm{HCS}-\mathrm{LiCl}$ showed a better sorption kinetics, which presumably is attributed to the formation of the liquid-phased $\mathrm{LiCl}$ solution and consequently slow diffusion of vapor in the bulk water phase. When the test was close to the end, the slope of HCS-LiCl water uptake curve comes down, which may be due to its near saturation point. When comparing the water vapor sorption behavior from this outdoor test with the one observed from STA-MHG, the sorption rate is decreased, which may be primarily resulted from the heat/mass transfer issue in the enlarged scale [48]. However, the HCS-LiCl still shows a higher water vapor sorption behavior in the actual outdoor condition.

Water vapor sorption isotherms of $\mathrm{HCS}-\mathrm{LiCl}$ were tested on a DVS analyzer to further investigate its water vapor sorption performance under varied conditions (Fig. S12a). Two representative temperatures in our test location, $25^{\circ} \mathrm{C}$ for nighttime and $35{ }^{\circ} \mathrm{C}$ for daytime in a shadowed area, were investigated. As can be seen, the equilibrium water uptake from the two temperature 
375

376

377

378

379

380

381

382

383

384

385

386

387

388

389

390

391

392

393

394

395

396

397

398

399

400

401

402

403

404

conditions was quite similar. The equilibrium water uptake at $\mathrm{RH} 20 \%$ is $\sim 0.4 \mathrm{~g} / \mathrm{g}$, indicating a reasonable water sorption performance at low humidity condition. The equilibrium water uptake at the highest $\mathrm{RH}$ condition in this test (i.e., $\mathrm{RH} 80 \%$ ) was $>2.0 \mathrm{~g} / \mathrm{g}$. The results of the isotherm measurement agree well with the STA results.

The stability of HCS-LiCl was tested by a STA-MHG system for 10 sorption/desorption cycles. The sorption/desorption behavior of the HCS-LiCl is shown in Fig. S12b. A plateau can be observed at the end of each cycle. The unchanged water vapor sorption kinetic and water uptake capacity in each individual cycle indicates the stability of HCS-LiCl even when the humidity as high as $80 \%$ at $25^{\circ} \mathrm{C}$ for 10 hours. And the structures of the spherical HCS-LiCl particles show no obvious change after the test and there is no sign of LiCl leakage (Fig. S13, Supplementary note 3). The results indicate that the $\mathrm{HCS}-\mathrm{LiCl}$ is stable towards the water sorption/desorption cycles even when the relative humidity is as high as $80 \%$ at $25^{\circ} \mathrm{C}$.

\subsection{Photothermal assisted water release.}

In practical applications, it might be necessary for powder formed water vapor sorbent to be fixated onto a substrate material and assembled into an AWG device. With the device, water is released out of the sorbent at a high temperature caused by photothermal heating when it is exposed to sunlight. $[49,50]$ In this work, we used a fibrous silica filter as the matrix to hold the nano sorbent (HCS-LiCl@ $\mathrm{SiO}_{2}$ ). The dimension of sorbent loaded filter was $8 \times 8 \mathrm{~cm}^{2}$, composed of $0.56 \mathrm{~g}$ fibrous silica filter and $0.64 \mathrm{~g}$ of dried $\mathrm{HCS}-\mathrm{LiCl}$ nano sorbent. The weight change of the HCS$\mathrm{LiCl} @ \mathrm{SiO}_{2}$ was real-time monitored and recorded by an electrical balance connected with a computer. The HCS-LiCl@ $\mathrm{SiO}_{2}$ was exposed to the ambient (i.e. $22{ }^{\circ} \mathrm{C}, \mathrm{RH} 60 \%$ ) for 3 hours, at the end of which $0.67 \mathrm{~g}$ water was sorbed, equivalent to $36 \%$ of its own weight at saturated state. The saturated $\mathrm{HCS}-\mathrm{LiCl} @ \mathrm{SiO}_{2}(1.87 \mathrm{~g})$ was exposed under simulated sunlight with a strength of 1 $\mathrm{kW} / \mathrm{m}^{2}$, under which the temperature of $\mathrm{HCS}-\mathrm{LiCl} @ \mathrm{SiO}_{2}$ quickly raised up to $50{ }^{\circ} \mathrm{C}$ within 2 minutes and stabilized at $\sim 72{ }^{\circ} \mathrm{C}$ after 25 minutes. Most of the sorbed water (i.e. >90\%) was released within 25 minutes, indicating a fast water release property (the "dry state" of the sample is defined by the minimum weight of the sample dried under $80^{\circ} \mathrm{C}$ ).

As the water evaporates, the $\mathrm{LiCl}$ concentration in HCS increases, resulting in a surpressed water evaporation rate, gradullay reduced evaporation heat loss and increased sorbent temperature. It has to be emphasized that in this work the heat was generated by the carbon shell of HCS-LiCl nano 
sorbent. In the conventional batch-processed AWH process, photothermal materials are separated with the sorbents. Heat is generated on the photothermal layer and subsequently transferred to the sorbents. Considering the existence of large heat resistance in the photothermal material-water vapor sorbent interface, heat loss during heating up the heat transfer media, and poor heat conductivity within the inner structure of AWH system, the overall utilization efficiency of solar energy is not high [32,38-42].
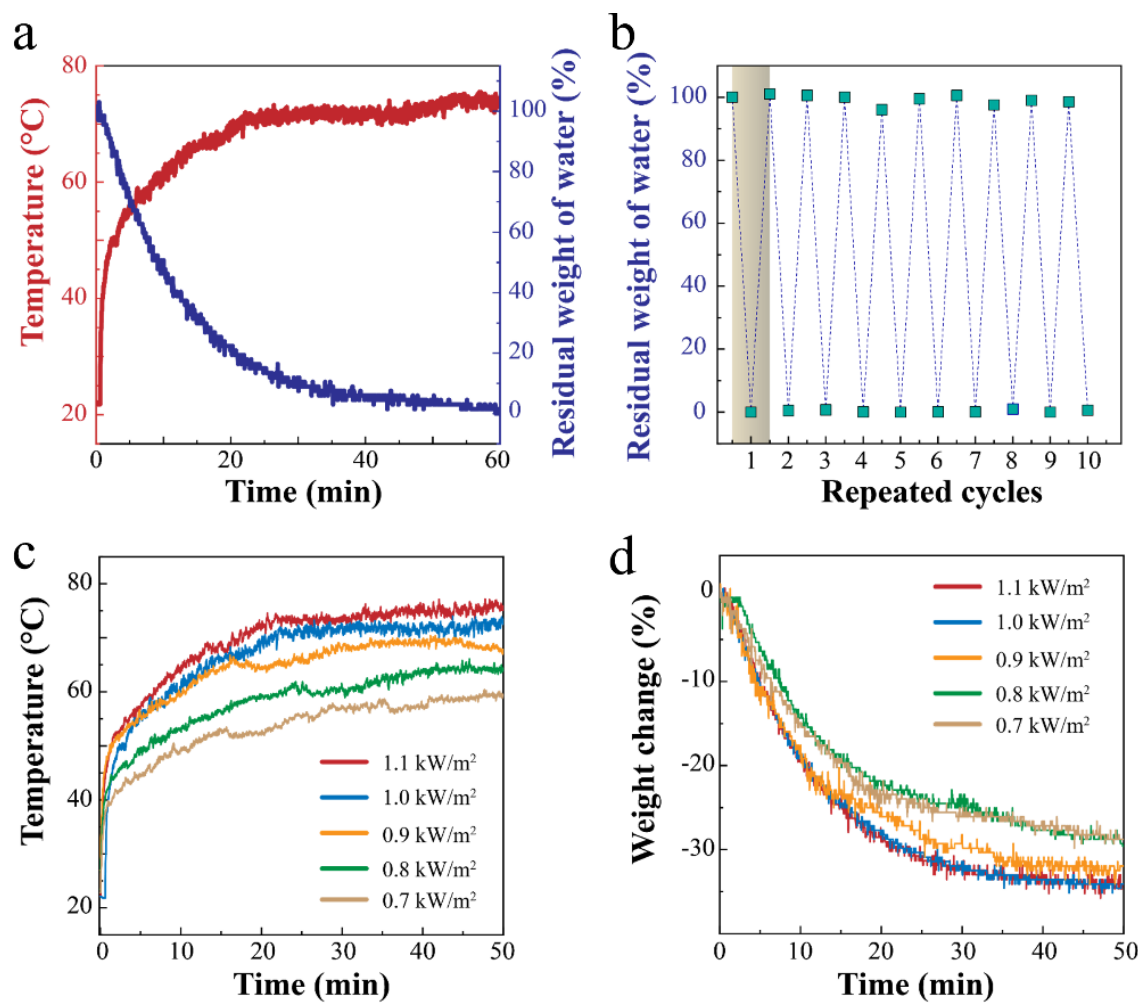

Fig. 5. (a) Weight change vs. temperature profile of HCS-LiCl loaded on the fibrous silica filter. (b) Stability test of the nano sorbent. The red dash line indicates 1 sorption/desorption cycle. The $\mathrm{Y}$-axis indicates the water sorbed by the nano sorbent. The sunlight strength was $1 \mathrm{~kW} / \mathrm{m}^{2}$. (c) Temperature and (d) weight change profiles of saturated $\mathrm{HCS}-\mathrm{LiCl} @ \mathrm{SiO}_{2}$ under varied light strength.

In this work, heat is generated at the sidewall of carbon capsule and carbon is a good heat conductor. Thus the heat is locally generated and distributed homogeneously on the carbon shell with minimized heat loss, leading to fast heating of inside $\mathrm{LiCl}$ salt from all directions. Fig. S14a-d present the IR images of $\mathrm{HCS}-\mathrm{LiCl}$ nano sorbents after exposure to the simulated sunlight for 0 , 10, 30, and 60 minutes, respectively. A high temperature (i.e. $70{ }^{\circ} \mathrm{C}$ ) can be easily achieved, 
422 indicates the great photothermal performance of HCS-LiCl nano sorbent. The stability of HCS-

$423 \mathrm{LiCl} @ \mathrm{SiO}_{2}$ test was carried out by repeating the sorption/desorption process for 10 times under 1

$424 \mathrm{~kW} / \mathrm{m}^{2}$ simulated light strength. After 10 sorption-desorption cycles test, the performance of HCS-

$425 \mathrm{LiCl}$ showed almost no degradation, demonstrating its outstanding operational stability (Fig. 5b).

426 The temperature profile and water release property of HCS-LiCl were further investigated under

427 simulated sunlight with varied light strength. A fast temperature increase can be observed under

428 all test conditions in the first several minutes. For the light strength of $0.7,0.8,0.9,1.0$, and 1.1

$429 \mathrm{~kW} / \mathrm{m}^{2}$, the temperature of the tested sample reached $39,42,46,50$, and $51{ }^{\circ} \mathrm{C}$ within the first 2

430 minutes, with their respective equilibrium temperatures at $58,60,65,70$, and $75^{\circ} \mathrm{C}$, respectively

431 (Fig. 5c). The weight change profile is shown in Fig. 5d, where the Y-axis of the graph indicates

432 the weight loss due to water evaporation relative to the saturated weight of $\mathrm{HCS}-\mathrm{LiCl} @ \mathrm{SiO}_{2}$. As

433 can be seen, the weight change value at the equilibrium state for $1.1,1.0$, and $0.9 \mathrm{~kW} / \mathrm{m}^{2}$ test were

434 quite close (i.e. $33-36 \%$ of its own weight, $92 \%-100 \%$ of total absorbed water weight), indicating

435 that the $\mathrm{HCS}-\mathrm{LiCl} @ \mathrm{SiO}_{2}$ can quickly release all its absorbed water as long as the sunlight strength

436 was higher than $0.9 \mathrm{~kW} / \mathrm{m}^{2}$. For the test under 0.8 and $0.7 \mathrm{~kW} / \mathrm{m}^{2}$, by the end of the test, the weight

437 change of $\mathrm{HCS}-\mathrm{LiCl} @ \mathrm{SiO}_{2}$ was $27 \%$ (75\% of total absorbed water weight), which is only slightly

438 lower than that of the test conducted under regular solar irradiation.

439 The results obtained from photothermal assisted water release experiment further confirm that the

$440 \mathrm{HCS}-\mathrm{LiCl}$ is a highly efficient water vapor sorbent with fast water capture/release property and

441 high stability. Furthermore, the ability to release water under weakened sunlight makes the HCS-

$442 \mathrm{LiCl}$ nano sorbent has broad application prospects.

\subsection{Batch-process based AWH device and its outdoor performance.}

444 An all-in-one device was further assembled by using easily available commercial materials for outdoor test. The AWH device included a metallic cookie box $\left(20 \times 20 \times 5 \mathrm{~cm}^{3}\right)$ as primary container, a glass dish (diameter $14 \mathrm{~cm}$ ) to separate the nano sorbents and collected water, and a

447 kitchen plastic wrap as transparent window and condensation surface. During water vapor sorption process, the device was placed under a shade exposed to the ambient air. Due to the absence of the sunlight, the nano sorbent was cooled down to the ambient temperature and thus could sorb water

450 vapor from the surrounding air (Fig. 6a, left). During desorption, the box was tightly sealed with the wrap and put out under direct solar irradiation. A temperature gradient was built up between 
452 the metal box wall, air-cooled plastic wrap surface and the photothermal-heated water vapor 453 sorbent, which provided the driving force of condensation process (Fig. 6a, right). Fig. 6b-1 and 454 b-2 present the digital photos of the device in water vapor sorption mode and water production 455 mode, respectively. The transmittance and reflectance UV-vis-NIR (250-2500 nm) spectra of the 456 plastic film were tested to estimate the percentage of solar energy absorbed by the plastic film (Fig. 457 S15). As can be seen, the transmittance of the plastic film maintained at $\sim 90 \%$ in the whole range 458 while its reflectance was around 10\%. The thin film only showed a light absorbance of around 7\% 459 within the wavelength of $2250-2500 \mathrm{~nm}$, meaning this film is almost transparent to the full spectrum of the sunlight.

(a)

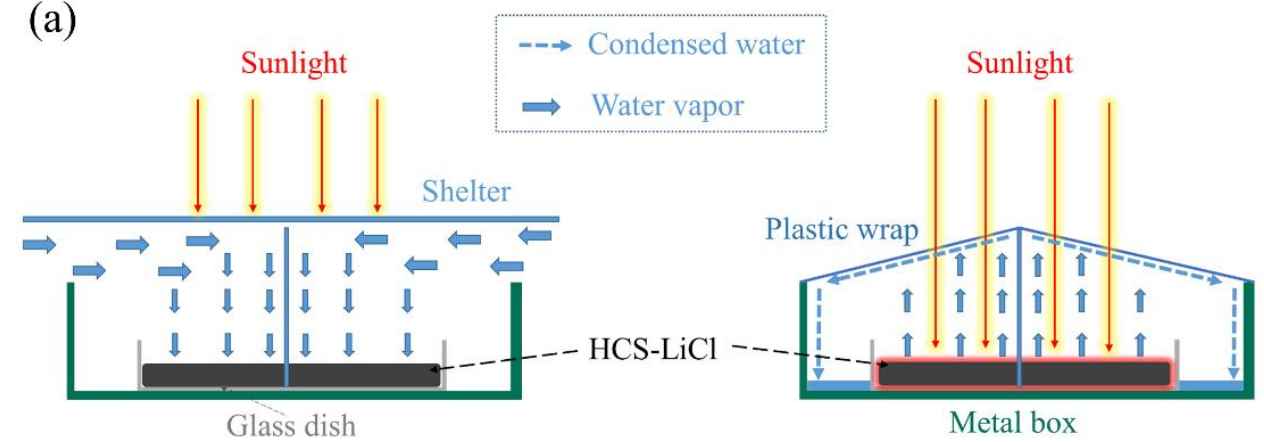

Glass dish

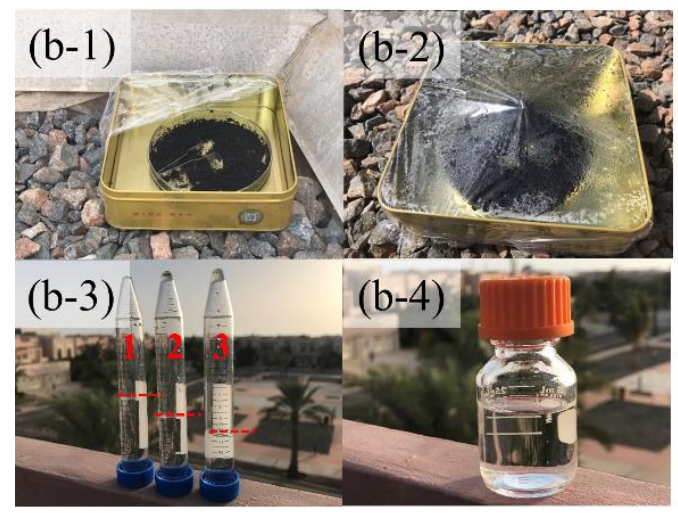

(c)

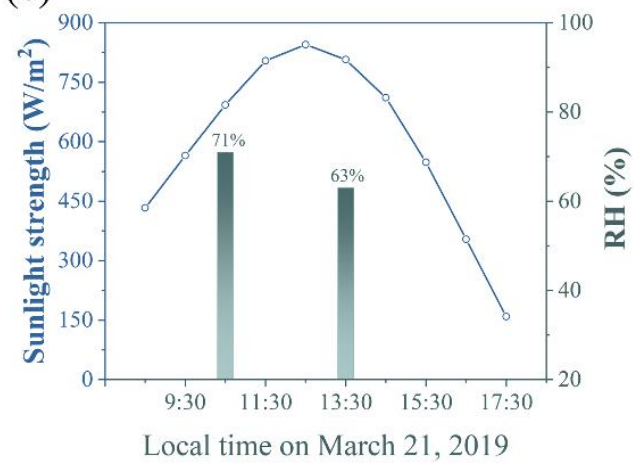

Fig. 6. (a) Schematic of batch-processed AWH device. Left: Water vapor sorption mode, plastic wrap was removed and the sorbent was sheltered from sunlight irradiation. Right: Desorption and water-production mode, plastic wrap covered the container. (b) Digital photos of batch-process based AWH device in water-production mode (b-1), water vapor sorption mode (b-2), water collected in batch 1-3 (b-3) (red dash line indicates water level), and accumulated water collected for all three batches (b-4). (c) Weather data of March 21, 2019. 
In the outdoor test, the device with $12.6 \mathrm{~g}$ of pre-dried HCS-LiCl nano sorbent was first kept outdoor overnight inside KAUST campus at Thuwal, KSA (21:00 March 20, 2019 to 8:10, March 21,2019 , with an average temperature of $25^{\circ} \mathrm{C}$ and an average relative humidity was $60-70 \%$, mixing ratio 12.11-13.76 g/ $\mathrm{kg}_{\text {air }}$ ) (Fig. 6c). The first sunlight-induced water production process was started on March 21, 2019 at 8:20 am local time (GMT+3), and around $7.7 \mathrm{~g}$ of water was collected within 80 minutes (8:20-9:40 am). The device was then subject to two more sorptiondesorption cycle (details can be found in Method and Supplementary note 4 ). The $2^{\text {nd }}$ and $3^{\text {rd }}$ cycles produced 6.5 and $5.4 \mathrm{~g}$ of fresh water (Fig. 6b-3). In the end, the device produced an accumulative amount of $\sim 19.6 \mathrm{~g}$ fresh water (Fig. 6b-4), which is 1.6 times the weight of the dry sorbent.

The selection of the time scale in each cycle was determined by the time efficiency and sunlight strength. Since the device relies upon solar energy as the heat source, desorption and water production mode is not operational during the night, thus the device was placed outdoor overnight to saturate its capacity. Based on the STA-MHG water vapor sorption test (Fig. 4), the optimized sorption rate and $\sim 70-80 \%$ of the maximum capacity can be achieved within this time scale of $<120$ min. Considering the time efficiency, a duration of 2 hours was used as the water vapor sorption time for the second and third water harvesting cycle.

For the water vapor desorption process, the time scale is mainly determined by the sunlight strength during the day. The sunlight strength was sufficient to support the water release process of the sorbent during the morning and noon. However, after 15:30, the light strength quickly attenuated to an insufficient level and the photothermal-induced sorbent temperature may not enough to quickly release the absorbed water. Thus, for the first and second water harvesting process, a duration of 80 min was used for the desorption process and for the third water production cycle we chose to extend the desorption time to $120 \mathrm{~min}$ and align the device facing to the sunlight.

By comparison, the water production rate of $\mathrm{HCS}-\mathrm{LiCl}$ in outdoor condition was only half of what predicted by the indoor STA test ( $\sim 38 \mathrm{~g}$, similar climate condition, $12.6 \mathrm{~g}$ of dried HCS-LiCl) (See Supplementary note 5 for details), indicating a significant potential for further improvement. The outdoor field experiment of $\mathrm{HCS}-\mathrm{LiCl}$ demonstrates that the sorbent is capable of providing multiple water vapor sorption/water production cycles within one day. Even though the AWH device needs further improvement, the device in the field experiment still shows an excellent water production yield (i.e. $1.6 \mathrm{~g}_{\text {water }} / \mathrm{g}_{\text {sorbent }}$ within one day). 
The quality of water from the outdoor experiment was inspected by the ICP-OES and TOC analyzer. The concentration of lithium (from the $\mathrm{LiCl}$ salt in the $\mathrm{HCS}-\mathrm{LiCl}$ sorbent) and iron (from the condensation chamber, i.e., cookie box) are checked. A deionized water sample generated from a Milli-Q system, a standard sample contains $5 \mathrm{ppm}$ of lithium and $5 \mathrm{ppm}$ of iron were used as the quality control (QC). For TOC analysis, the TOC analyzer was pre-calibrated by the TOC standard sample with a concentration of $0.10,0.25,0.50,1.0,5.0,10$ and $20 \mathrm{ppm}$, respectively. Deionized water and $10 \mathrm{ppm}$ TOC standard sample were used as quality control. The quality inspection results of the water sample from the outdoor experiment are listed in Table 1. As can be seen, the water quality fulfills the WHO requirement. The TOC concentration is $1.96 \mathrm{ppm}$, which may resulted by the absorption of airborne organic compounds during water vapor sorption process.

Table 1. Water quality analysis of water production from the outdoor experiment

\begin{tabular}{ccc}
\hline & Ion concentration test \\
\hline & Iron $(\mathrm{Fe})$ & Lithium $(\mathrm{Li})$ \\
DI water & Below $0.01 \mathrm{ppm}$ & Below 0.01 ppm \\
Water from AWG & $0.02 \mathrm{ppm}$ & $0.01 \mathrm{ppm}$ \\
5 ppm QC & $5.01 \mathrm{ppm}$ & $4.98 \mathrm{ppm}$ \\
WHO guideline & $0.30 \mathrm{ppm}$ & N/A \\
\hline \multicolumn{3}{c}{ TOC test } \\
DI water & TOC concentration \\
Water from AWG & $0.12 \mathrm{ppm}$ \\
10 ppm QC & $1.96 \mathrm{ppm}$ \\
\hline
\end{tabular}

\subsection{HCS-LiCl based continuous AWG device.}

512 The conceptual design of the continuous AWG device is shown in Fig. 7a and Fig. S16. Fig. 7b

513 presents a digital photo of the real device. The dimension of the device is $11.15 \times 10.75 \times 10.00$

$514 \mathrm{~cm}^{3}$, with a rotational cylinder encapsulated $(\Phi=42 \mathrm{~mm}, \mathrm{~L}=74 \mathrm{~mm}) .2 .93 \mathrm{~g}$ of sorbent was 515 homogeneously loaded on the rotational cylinder with loading density of $0.03 \mathrm{~g} / \mathrm{cm}^{2}$ (Details can 516 be found in Supplementary note 6). In this continuous device, the rotational cylinder loaded with 517 water vapor sorbent is placed between two grooved frames. The top sector of the rotational cylinder 518 is exposed to the sunlight and condensation chamber to release water, while the bottom sector is 519 exposed to the ambient to harvest water vapor (Fig. 7b). The incident sunlight penetrates the 520 transparent cap and irradiates on the top sector of the rotational cylinder (Fig. 7c). The water521 saturated water vapor sorbent is quickly heated up and releases water in vapor phase. The released 
water vapor is condensed on the top plastic cover and on the sidewall of copper condensation

523 chamber (Fig. 7d), the condensed water droplets on the sidewalls slide down to the PTFE collector

524 and direct to the water outlet. The dehydrated water vapor sorbent is rotated to the bottom side

525 along with the rotation of the center cylinder, and starts the next water vapor sorption and

526 photothermal-assisted water release cycle. The water content and temperature profile of water

527 vapor sorbent are colored by two concentric rings.
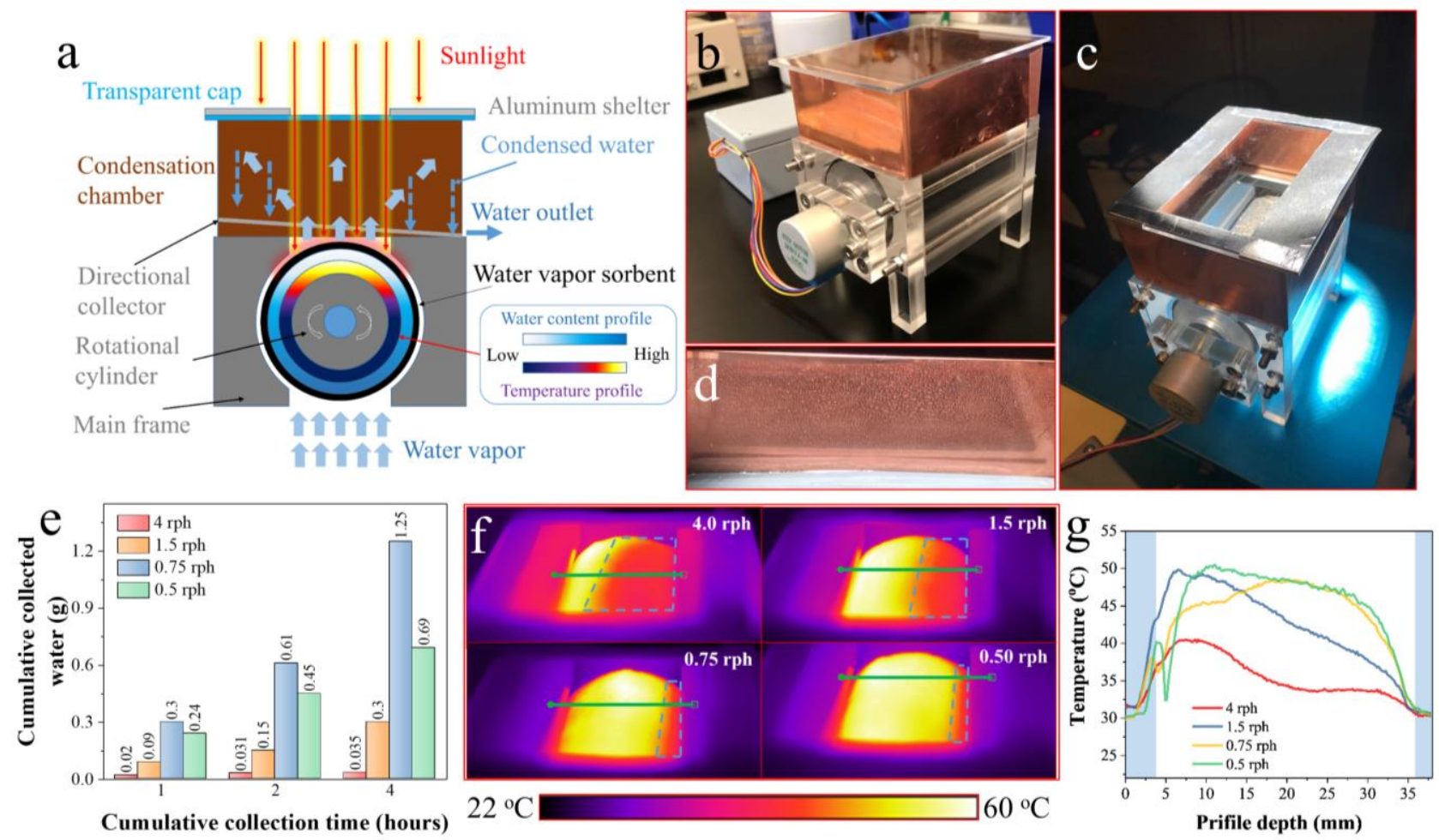

529 Fig. 7. (a) Schematic of cross sectional view of the sorption-based continuous AWG prototype. 530 (b)-(d) Digital photo of final assembled AWG device, AWG device in operation, and water condensed on the side wall of the condensation chamber, respectively. (e) Cumulative water production yield of AWG device under varied cylinder rotation rate. (f) IR image of water vapor sorbent exposed to the sunlight under varied cylinder rotation rate. $(\mathrm{g})$ Temperature profile of water 534 vapor sorbent exposed to the sunlight under varied cylinder rotation rate. The simulated sunlight strength in this test was $1 \mathrm{~kW} / \mathrm{m}^{2}$.

The prototype was tested in the lab condition where environmental conditions are controlled by 537 the centralized heating, ventilation, and air conditioning (HVAC) system. The temperature and the relative humidity is maintained at $22{ }^{\circ} \mathrm{C}, 60 \%$, respectively. Given the small size of the device and 
the outstanding heat conductivity of metal condensation chamber, the condenser temperature was similar to the environmental temperature (i.e., $22{ }^{\circ} \mathrm{C}$ ). For each rotation rate condition, 3 batches of the experiment were conducted under a specific collection duration (i.e., 1, 2, and 4 hours). A pre-weighted filter paper was used to collect the condensed water by the end of each test. The water production yield of each individual test can be calculated from the weight difference of the filter paper. The water production performance of the continuous AWG prototype is compared in Fig. 7e. A quantity of 0.24, 0.30, 0.09, and $0.02 \mathrm{~g}$ water was produced during first hour with the cylinder rotation rate of $0.50,0.75,1.25$, and 4 revolution per hour $(\mathrm{rph})$, respectively. These trends can be observed even when the collection duration time was extended to 2 and 4 hours. By the end of the 4-hour test, $0.69,1.25,0.3$, and $0.035 \mathrm{~g}$ of water was collected under rotation rate of 0.5 , $0.75,1.5$, and $4 \mathrm{rph}$, respectively. A detailed list of water harvesting rate in the varied conditions has been displayed in Table 2. An IR camera was used to observe the temperature of the water vapor sorbent under sunlight irradiation with varied rotation rate (Fig. 7f). The dash line in each of the IR images covered the "cold" region (i.e., less than $40^{\circ} \mathrm{C}$ ) of the water vapor sorbent, and the size of "cold" region expanded along with the increased cylinder rotation rate (Supplementary note 7). The temperature gradient across the sorbent surface (green line across the IR image) also confirmed the temperature difference under varied rotation rate $(\mathbf{F i g} . \mathbf{7 g})$. The desorption rate of water from the sorbent was lower due to the lowered temperature under faster rotation rate. However, if the rotation rate of the cylinder is too slow (e.g., $0.5 \mathrm{rph}$ ), on the one hand, the water vapor sorbent exposed to the sunlight will be exhausted due to over exposure. On the other hand, the adjacent water vapor sorbent is collaterally heated up and thus releases water before moving into the condensation chamber due to the internal heat conduction, thus leading to a decreased water production yield. The water production yield was estimated to be $0.84 \mathrm{~g}_{\text {water }} / \mathrm{g}$ sorbent within 8 hours. Ongoing effort is being made on improving the overall efficiency of the device.

Table 2 . The detailed water harvesting rate in the varied test conditions.

\begin{tabular}{ccccccccc}
\hline & \multicolumn{2}{c}{$0.5 \mathrm{rph}$} & \multicolumn{2}{c}{$0.75 \mathrm{rph}$} & \multicolumn{2}{c}{$1.5 \mathrm{rph}$} & \multicolumn{2}{c}{ rph } \\
\hline Collection & Rotational & Harvested & Rotational & Harvested & Rotational & Harvested & Rotational & Harvested \\
time (h) & cycles (r) & water (g) & cycles (r) & water (g) & cycles (r) & water (g) & cycles (r) & water (g) \\
1 & 0.5 & 0.24 & 0.75 & 0.3 & 1.5 & 0.09 & 4 & 0.02 \\
2 & 1.0 & 0.45 & 1.5 & 0.61 & 3 & 0.15 & 8 & 0.031 \\
4 & 2.0 & 0.69 & 3.0 & 1.25 & 6 & 0.3 & 16 & 0.035 \\
\hline
\end{tabular}


564 In summary, the sorption-based continuous AWG device we presented in this work can harvest 565 water from the air continuously. To the best of our knowledge, this is the first sorption-based continuous AWG device ever reported, whose performance needs further improvement.

567

568

\section{Conclusion}

569 In conclusion, a nano-scaled photothermal water vapor sorbent with a spherical photothermal shell 570 and a hygroscopic salt core was designed and synthesized. The water vapor sorption and desorption 571 kinetics were largely enhanced comparing with the previously reported water vapor sorbents. The 572 sorbent is capable of absorbing water vapor from air as much as $100 \%$ of its own weight within 3 573 hours under RH 60\%. The absorbed water can be quickly released within 30 minutes under 1 $574 \mathrm{~kW} / \mathrm{m}^{2}$ sunlight irradiation. A batch process-based AWG demonstrated the superior water 575 production yield as much as $1.6 \mathrm{~kg}$ water per kilogram sorbent per day, which was enabled by its 576 multiple atmospheric water harvesting cycles within one day. A sorption-based conceptual 577 prototype of continuous AWG device was assembled and investigated in the laboratory condition. 578 The continuous production of clean water was successfully demonstrated. 


\section{Declaration of interests.}

581 Peng Wang, Renyuan Li, and Yusuf Shi have a patent application related to the work presented in 582 this paper.

\section{Acknowledgments.}

584 The authors are grateful to KAUST for very generous financial support. We appreciate the 585 assistance of KAUST mechanical workshop for the design and fabrication of continuous AWG 586 device. In addition, we thank KAUST solar center for providing the access to their equipment.

\section{Appendix A. Supplementary data}

588 Schematics of $\mathrm{LiCl}$ infiltration process. SEM image of $\mathrm{HCS}-\mathrm{LiCl} @ \mathrm{SiO}_{2}$. The relative light 589 absorption rate for the sample to sunlight. Wetting behavior of $\mathrm{LiCl}$ water solution on the HCS$590 \mathrm{LiCl} @ \mathrm{SiO}_{2}$. Nitrogen sorption isotherm of HCS. Calculation of the volume percentage of $\mathrm{LiCl}$ in 591 the HCS vacancy. Full-range curve of derivative weight change. Zoom-in plot of water vapor 592 absorption section. Calculation of the dimension of interparticle space. Schematics of 593 sorption/desorption behaviors of nano sorbent and bulk-phased sorbent. Water vapor sorption 594 behavior of $\mathrm{HCS}-\mathrm{LiCl}$ and $\mathrm{LiCl}$ in outdoor condition. Water vapor sorption isotherms of HCS595 LiCl. STA-MHG based stability test results. SEM observation of HCS-LiCl under varied 596 conditions. IR images. UV-vis-NIR spectrum of plastic film used in the field test. Experimental 597 details and discussion on the batch-mode AWG. Estimation of the water production yield of HS$598 \mathrm{LiCl}$ nano sorbent under STA test condition. Detailed assembly of continuous AWG device. 599 Device design of continuous AWG. Calculation of sorbent exposure time under sunlight in the 600 continuous AWG device. 


\section{References.}

603 [1] M.M. Mekonnen, A.Y. Hoekstra, Four billion people facing severe water scarcity. Sci. Adv. 2 604 (2016) e1500323.

605 [2] S.N. Gosling, N.W. Arnell, A global assessment of the impact of climate change on water scarcity. 606 Climatic Change 134 (2016) 371-385.

607 [3] J.-F. Pekel, A. Cottam, N. Gorelick, A.S. Belward, High-resolution mapping of global surface water 608 and its long-term changes. Nature 540 (2016) 418-422.

609 [4] A. Alkhudhiri, N. Darwish, N. Hilal, Membrane distillation: a comprehensive review. Desalination $610287(2012) 2-18$.

611 [5] A.D. Khawaji, I.K. Kutubkhanah, J.-M. Wie, Advances in seawater desalination technologies. 612 Desalination 221 (2008) 47-69.

613 [6] M. Elimelech, W.A. Phillip, The future of seawater desalination: energy, technology, and the 614 environment. Science 333 (2011) 712-717.

615 [7] K. Lutchmiah, A.R.D. Verliefde, K. Roest, L.C. Rietveld, E.R. Cornelissen, Forward osmosis for 616 application in wastewater treatment: a review. Water Res. 58 (2014) 179-197.

617 [8] R. Li, L. Zhang, P. Wang, Rational design of nanomaterials for water treatment. Nanoscale 7 (2015) $618 \quad 17167-17194$.

619 [9] K. Lutchmiah, A.R.D. Verliefde, K. Roest, L.C. Rietveld, E.R. Cornelissen, Forward osmosis for 620 application in wastewater treatment: a review. Water Res. 58 (2014) 179-197.

621 [10] UNICEF and WHO, Progress on drinking water and sanitation: 2012 Update. UNICEF (2012).

622 [11] WWAP (UNESCO World Water Assessmen Programme), The United Nations world water 623 development report 2019: leaving no one behind. UNESCO (2019).

624 [12] K. Daley, H. Castleden, R. Jamieson, C. Furgal, L. Ell, Water systems, sanitation, and public health 625 risks in remote communities: Inuit resident perspectives from the Canadian Arctic. Soc. Sci. \& Med. 135 626 (2015) 124-132.

627 [13] W.A. Abderrahman, Water management in Ar-Riyadh. Int. J. Water Resour. D. 22 (2006) 277-289. 628 [14] GWI, Becoming a world-class water utility. Global Water Intelligence Magazine 12 (2011).

629 [15] G. Hutton, C. Chase, The Knowledge Base for achieving the sustainable development goal targets 630 on water supply, sanitation and hygiene. Int. J. of Env. Res. Pub. He. 13 (2016) 536-571.

631 [16] S.H. Schneider, T.L. Root, M.D. Mastrandrea, Encyclopedia of Climate and Weather. 2011.

632 [17] Z. Şen, Chapter 1-Water science basic information. In Practical and Applied Hydrogeology, Ed. 633 Elsevier: Oxford, 2015, pp 1-41. 

Academic Press: San Diego, 2007, pp 19-57.

636 [19] P. Wang, Emerging investigator series: the rise of nano-enabled photothermal materials for water 637 evaporation and clean water production by sunlight. Environ. Sci.: Nano 5(2018) 1078-1089.

638 [20] S. V. Boriskina, A. Raza, T. Zhang, P. Wang, L. Zhou, J. Zhu, Nanomaterials for the water-energy 639 nexus. MRS Bulletin, 44 (2019) 59-66.

640 [21] D. Beysens, I. Milimouk, V.S. Nikolayev, S. Berkowicz, M. Muselli, B. Heusinkveld, A.F.G. 641 Jacobs, Comment on "The moisture from the air as water resource in arid region: hopes, doubt and facts" 642 by Kogan and Trahtman. J. Arid Environ. 67 (2006) 343-352.

643 [22] O. Klemm, R.S. Schemenauer, A. Lummerich, P. Cereceda, V. Marzol, D. Corell, J. van Heerden, 644 D. Reinhard, T. Gherezghiher, J. Olivier, P. Osses, J. Sarsour, E. Frost, M.J. Estrela, J.A. Valiente, G.M. 645 Fessehaye, Fog as a fresh-water resource: overview and perspectives. Ambio 41 (2012) 221-234.

646 [23] F. T. Malik, R.M. Clement, D.T. Gethin, W. Krawszik, A.R. Parker, Nature's moisture harvesters: 647 a comparative review. Bioinspir. Biomim 9 (2014) 031002.

648 [24]. Y. Tu, R. Wang, Y. Zhang, J. Wang, Progress and expectation of atmospheric water harvesting. 649 Joule 2 (2018) 1452-1475.

650 [25] Y. Wang, L. Zhang, J. Wu, M.N. Hedhili, P. Wang, A facile strategy for the fabrication of a 651 bioinspired hydrophilic-superhydrophobic patterned surface for highly efficient fog-harvesting. J. Mater. 652 Chem. A 3 (2015) 18963-18969.

653 [26] L. Zhang, J. Wu, M.N. Hedhili, X. Yang, P. Wang, Inkjet printing for direct micropatterning of a 654 superhydrophobic surface: toward biomimetic fog harvesting surfaces. J. Mater. Chem. A 3 (2015) 28446552852.

656 [27] T. Xu, Y. Lin, M. Zhang, W. Shi, Y. Zheng, High-efficiency fog collector: water unidirectional 657 transport on heterogeneous rough conical wires. ACS Nano 10 (2016) 10681-10688.

658 [28] J. Ju, H. Bai, Y. Zheng, T. Zhao, R. Fang, L. Jiang, A multi-structural and multi-functional 659 integrated fog collection system in Cactus. Nat. Commun. 3 (2012) 1247-1252.

660 [29] F. Bagheri, Performance investigation of atmospheric water harvesting systems. Water Resources 661 and Industry 20 (2018) 23-28.

662 [30] R.V. Wahlgren, Atmospheric water vapour processor designs for potable water production: a 663 review. Water Res. 35 (2001) 1-22.

664 [31] B. Gido, E. Friedler, D.M. Broday, Liquid-desiccant vapor separation reduces the energy 665 requirements of atmospheric moisture harvesting. Environ. Sci. Technol. 50 (2016) 8362-8367.

666 [32] J.Y. Wang, J.Y. Liu, R.Z. Wang, L.W. Wang, Experimental investigation on two solar-driven 667 sorption based devices to extract fresh water from atmosphere. Appl. Therm. Eng. 127 (2017) 1608-1616. 

the atmosphere. Desalination 212 (2007) 176-182.

670 [34] L. Yi, S. Ci, S. Luo, P. Shao, Y. Hou, Z. Wen, Scalable and low-cost synthesis of black amorphous 671 Al-Ti-O nanostructure for high-efficient photothermal desalination. Nano Energy 41 (2017) 600-608.

672 [35] X. Wu, M.E. Robson, J. L. Phelps, J.S. Tan, B. Shao, G. Owens, H. Xu, A flexible photothermal 673 cotton-CuS nanocage-agarose aerogel towards portable solar steam generation. Nano Energy 56 (2019) $674 \quad 708-715$.

675 [36] M. He, Y.-J. Lin, C.-M. Chiu, W. Yang, B. Zhang, D. Yun, Y. Xie, Z.-H. Lin, A flexible photo676 thermoelectric nanogenerator based on $\mathrm{MoS}_{2} / \mathrm{PU}$ photothermal layer for infrared light harvesting. Nano 677 Energy 49 (2018) 588-595.

678 [37] H. Furukawa, F. Gándara, Y.-B. Zhang, J. Jiang, W.L. Queen, M.R. Hudson, O.M. Yaghi, Water 679 adsorption in porous metal-organic frameworks and related materials. J. Am. Chem. Soc. 136 (2014) 43696804381.

681 [38] H. Kim, S. Yang, S.R. Rao, S. Narayanan, E.A. Kapustin, H. Furukawa, A.S. Umans, O.M. Yaghi, 682 E.N. Wang, Water harvesting from air with metal-organic frameworks powered by natural sunlight. Science 683 356 (2017) 430-434.

684 [39] F. Fathieh, M.J. Kalmutzki, E.A. Kapustin, P.J. Waller, J. Yang, O.M. Yaghi, Practical water 685 production from desert air. Sci. Adv. 4 (2018) eaat3198.

686 [40] H. Kim, S.R. Rao, E.A. Kapustin, L. Zhao, S. Yang, O.M. Yaghi, E.N. Wang, Adsorption-based 687 atmospheric water harvesting device for arid climates. Nat. Commun. 9 (2018) 1191-1198.

688 [41] R. Li, Y. Shi, L. Shi, M. Alsaedi, P. Wang, Harvesting water from air: using anhydrous salt with 689 sunlight. Environ. Sci. Technol. 52 (2018) 5398-5406.

690 [42] R. Li, Y. Shi, M. Alsaedi, M. Wu, L. Shi, P. Wang, Hybrid hydrogel with high water vapor 691 harvesting capacity for deployable solar-driven atmospheric water generator. Environ. Sci. Technol. 52 692 (2018) 11367-11377.

693 [43] F. Zhao, X. Zhou, Y. Liu, Y. Shi, Y. Dai, G. Yu, Super moisture-absorbent gels for all-weather 694 atmospheric water harvesting. Adv. Mater. 31 (2019) 1806446.

695 [44] K. Matsumoto, N. Sakikawa, T. Miyata, Thermo-responsive gels that absorb moisture and ooze 696 water. Nat. Commun. 9 (2018) 2315-2321.

697 [45] A.-H. Lu, T. Sun, W.-C. Li, Q. Sun, F. Han, D.-H. Liu, Y. Guo, Synthesis of discrete and dispersible 698 hollow carbon nanospheres with high uniformity by using confined nanospace pyrolysis. Angew. Chem. 699 Int. Edit. 50 (2011) 11765-11768. 
700 [46] W. Neng, M. Martini, S. Wei-ning, X. Ling, S. Li-tao, S. Yu-ting, The in situ TEM observation of 701 rapid lithium encapsulation and release in $\mathrm{LiCl}$ nanoshells and nanotubes. CrystEngComm 15 (2013) 78727027878.

703 [47] B. Tang, L. Zhang, R. Li, J. Wu, M.N. Hedhili, P. Wang, Are vacuum-filtrated reduced graphene 704 oxide membranes symmetric? Nanoscale 8 (2016) 1108-1116.

705 [48] A. LaPotin, H. Kim, S.R. Rao, E.N. Wang, Adsorption-Based Atmospheric Water Harvesting: 706 Impact of Material and Component Properties on System-Level Performance. Acc. Chem. Res. 52 (2019) $707 \quad 1588-1597$.

708 [49] H. Qi, T. Wei, W. Zhao, B. Zhu, G. Liu, P. Wang, Z. Lin, X. Wang, X. Li, X. Zhang, and J. Zhu. 709 An interfacial solar-driven atmospheric water generator based on a liquid sorbent with simultaneous 710 adsorption-desorption. Adv. Mater. (2019) 1903378. DOI: 10.1002/adma.201903378.

711 [50] X. Wang, X. Li, G. Liu, J. Li, X. Hu, N. Xu, W. Zhao, B. Zhu, and J. Zhu. An interfacial solar 712 heating assisted liquid sorbent atmospheric water generator. Angew. Chem. Int. Ed. 58 (2019) 12054-12058. 